\section{Development of Reactions of Silacyclopropanes as New Methods for Stereoselective Organic Synthesis}

\author{
ANNALIESE K. FRANZ AND K. A. WOERPEL* \\ Department of Chemistry, University of California, \\ Irvine, California 92697-2025
}

Received December 29, 1999

ABSTRACT

In this Account, we describe the development of stereospecific, stereoselective, regioselective, and chemoselective carbon-carbon bond-forming reactions of silacyclopropanes that occur under mild conditions. By appropriate choice of metal salt catalyst, the regiochemistry of these reactions may be tuned to give the desired product. Stereoselective nucleophilic substitution reactions and stereospecific oxidation of the $\mathrm{C}-\mathrm{Si}$ bond to a carbon-oxygen bond demonstrate that the products of these reactions serve as useful intermediates for the synthesis of polyoxygenated organic molecules.

\section{Introduction}

The strain energy released upon cleavage of threemembered ring compounds ${ }^{1,2}$ can be harnessed to accomplish powerful stereoselective transformations in organic synthesis. For example, cyclopropanes have seen numerous applications in synthesis, ${ }^{3,4}$ as have their counterparts, the oxiranes ${ }^{5}$ and aziridines. ${ }^{6}$ In contrast, the synthetic potential of strained three-membered ring silanes (silacyclopropanes) as intermediates for stereoselective synthesis has not been examined. We found this situation to be paradoxical considering the unique reactivity of silicon compounds and their important role in organic chemistry. ${ }^{7,8}$ Although significant contributions to silacyclopropane chemistry have been reported by Seyferth et al., ${ }^{9-13}$ Ando et al., ${ }^{14}$ and others, ${ }^{15-17}$ the reactions of silacyclopropanes have not been extended to organic synthesis.

Since the preparation of the prototypal silacyclopropane 1 in 1975 by Seyferth, ${ }^{9}$ the knowledge of the

Annaliese Franz was born in Macomb, IL, in 1974 and raised in Columbia, M 0 . She received her B.S. degree in chemistry from Trinity University in San Antonio, TX, where she worked in the laboratory of Professor Michael P. Doyle (asymmetric metal-carbene transformations). She is currently a graduate student in the Woerpel group at the University of California, Irvine, and is the recipient of an Abbott Laboratories Graduate Fellowship.

Keith Woerpel was born in Boston, MA, in 1964. After receiving his B.S. in chemistry from the University of Virginia working in the laboratories of Professor Glenn J. McGarvey, he attended Harvard University and received his Ph.D. in 1992 under the direction of Professor David A. Evans. He spent two years as a postdoctoral research associate in the laboratories of Professor Robert $G$. Bergman at the University of California, Berkeley. He moved to the University of California, Irvine, in 1994, where he is currently an Associate Professor of Chemistry. His research addresses problems in stereoselective organic synthesis. fundamental chemistry exhibited by this highly strained ${ }^{18}$ functional group has grown to include carbon-carbon bond formation reactions ${ }^{13,14,19,20}$ and stereospecific protonolysis. ${ }^{21}$ New methods for silacyclopropane synthesis have also been developed 22 that allow for the stereospecific silacyclopropanation of alkenes, leading to cis- and trans-2. ${ }^{23}$ To apply the reactions of silacyclopropanes to
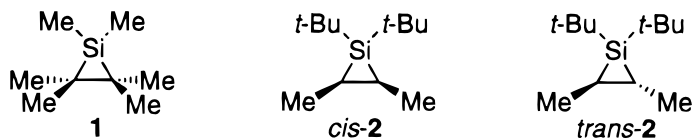

organic synthesis, however, many key issues remained to be elucidated, including the stereo- and regiochemistry of ring-opening, functional group compatibility, and reaction generality. Furthermore, the products of silacyclopropane reactions had not been converted into synthetically useful compounds that did not possess silicon atoms.

We initiated our studies to explore the carbon-carbon bond-forming reactions of silacyclopropanes as new methods for the stereoselective synthesis of polyoxygenated organic compounds. We were particularly attracted to the demonstration that carbonyl compounds would insert into the $\mathrm{C}-\mathrm{Si}$ bond of silacyclopropane $\mathbf{1}$, a reaction first discovered by Seyferth et al. ${ }^{13}$ We envisioned that we could insert various carbonyl compounds into chiral silacyclopropanes such as $\mathbf{3}$ to obtain oxasilacyclopentanes 4 (eq 1). If the insertion reaction were stereospecific,

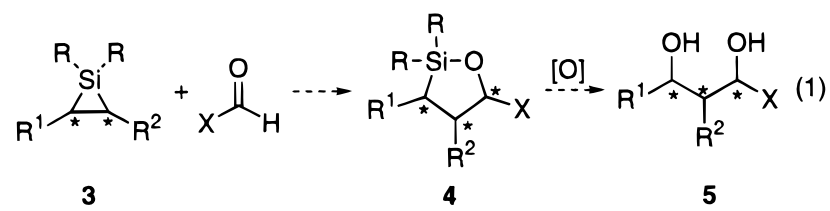

then different diastereomers of $\mathbf{4}$ could be prepared from the appropriate silacyclopropanes $\mathbf{3}$. The synthetic utility of these transformations would be revealed upon oxidation of the $\mathrm{C}-\mathrm{Si}$ bond ${ }^{24-27}$ to form diol $\mathbf{5}$ with three contiguous stereogenic centers.

The plan outlined in eq 1 raised a number of fundamental issues that would need to be addressed before realization of our goal. At the time we commenced our studies, the carbonyl insertion reaction ${ }^{13}$ had not been demonstrated for silacyclopropanes other than $\mathbf{1}$. It was not clear whether the stereochemistry of the starting silacyclopropane $\mathbf{3}$ would translate to the insertion product 4, particularly since Seyferth et al. had shown that the carbonyl insertion reaction with $\mathbf{1}$ might involve diradical intermediates. ${ }^{13}$ In addition, questions regarding the regiochemistry, chemoselectivity, and functional group tolerance of the insertion reaction had not been addressed. We planned to investigate these key issues in order to develop the insertion methodology with silacyclopropanes. The synthetic utility of this methodology could then be extended by preparing silacyclopropanes as single enantiomers, an area which also had not been examined previously. 
Over the course of the past few years, we have explored the reactions of silacyclopropanes and shown the synthetic utility of these reactions for the stereoselective synthesis of functionalized diols and triols. We have focused on the reactions of Boudjouk-type silacyclopropanes $^{23}$ such as cis- and trans- 2 because they were easily prepared in one step from alkenes and could be obtained as single diastereomers. Our investigations have illuminated new aspects of the fundamental reactivity of these strained silanes, in particular the stereochemistry of their reactions. In this Account, we describe the development of stereospecific, stereoselective, regioselective, and chemoselective carbon-carbon bond-forming reactions of silacyclopropanes that occur under mild conditions. We also demonstrate that the products of these reactions serve as useful intermediates for the synthesis of polyoxygenated organic molecules with several stereogenic centers.

\section{Reactions of Silacyclopropanes}

To determine whether silacyclopropanes would undergo stereospecific insertions, we first focused on ring-opening reactions with aldehydes. Although silacyclopropanes cisand trans 2 reacted with benzaldehyde under thermal conditions $\left(\geq 100{ }^{\circ} \mathrm{C}\right)$, the desired oxasilacyclopentane products 6-9 were accompanied by significant quantities of side products. In the presence of Lewis bases, ${ }^{19}$ however, the insertion reactions with benzaldehyde proceeded rapidly at or below room temperature with inversion of configuration (eqs 2 and 3). ${ }^{28,29}$ This acceleration is consistent with the initial formation of a more reactive pentacoordinate siliconate intermediate between the catalyst and the silacyclopropane. ${ }^{30}$
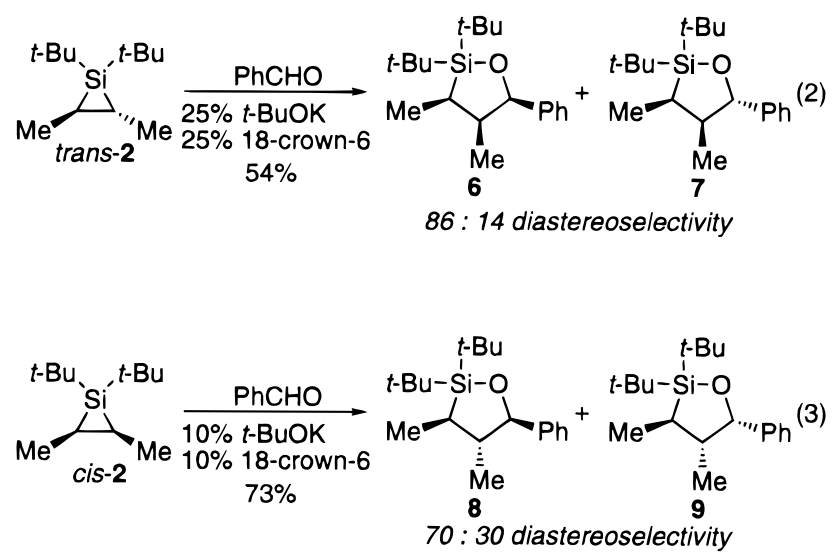

The development of insertion reactions with benzaldehyde served as an important advance in our studies because it proved that silacyclopropane stereochemistry would translate to product stereochemistry. Unfortunately, this Lewis base-catalyzed transformation was not general. Under the basic conditions optimized for benzaldehyde, aldehydes such as crotonaldehyde and isobutyraldehyde afforded only silyl enol ether products. ${ }^{29}$ Attempts to catalyze insertion with less basic reagents such as $\mathrm{Bu}_{4} \mathrm{NF}$, $\mathrm{Bu}_{4} \mathrm{NCl}$, and HMPA resulted in either no reaction or enolization.

In our search for nonbasic nucleophilic catalysts to effect insertion reactions of silacyclopropane trans-2, we discovered that formamides insert with high diastereoselectivity (eq 4). ${ }^{31}$<smiles>CC(C)[Si](C(C)(C)C)(C(C)(C)C)C(C)(C)C</smiles>
trans-2

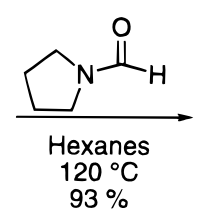

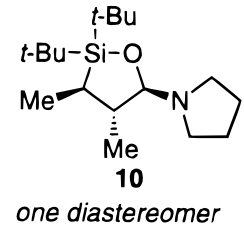

This reaction was unexpected since the carbonyl group of an amide is unreactive to most nucleophiles. ${ }^{32}$ The formation of oxasilacyclopentane $\mathbf{1 0}$ from trans- $\mathbf{2}$ indicated that this reaction proceeds with retention of silacyclopropane configuration, the opposite to the stereochemical course exhibited with aldehydes (eqs 2 and 3). The stereospecificity of the formamide insertion could not be rigorously determined, however, because the cis stereoisomer of the starting material decomposed at elevated temperatures before insertion (eq 5). To explain the

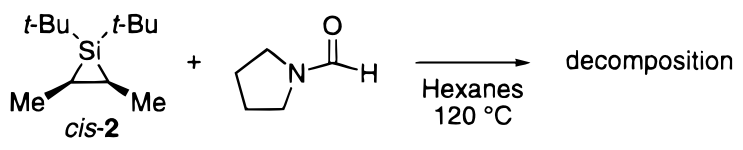
(5)

stereochemistry observed for insertion into trans-2 (eq 4), we proposed ${ }^{31}$ that this reaction proceeds via a Lewis acid-base complex $\mathbf{1 1}^{33-35}$ The formation of adduct $\mathbf{1 1}$ also accounts for the different reactivity observed for trans-2 with formamides as compared to that for aldehydes. Coordination of the amide to the electrophilic strained-ring silane both enhances the nucleophilicity of the silacyclopropane and activates the formyl group for internal nucleophilic attack. ${ }^{36,37}$

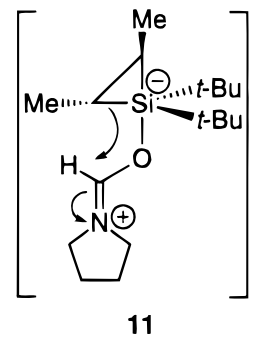

Further investigations determined that formamides insert into the more substituted $\mathrm{C}-\mathrm{Si}$ bond of unsymmetrical silacyclopropane $\mathbf{1 2}$ with high regioselectivity (eq 6). Selective cleavage of the more substituted $\mathrm{C}-\mathrm{Si}$ bond

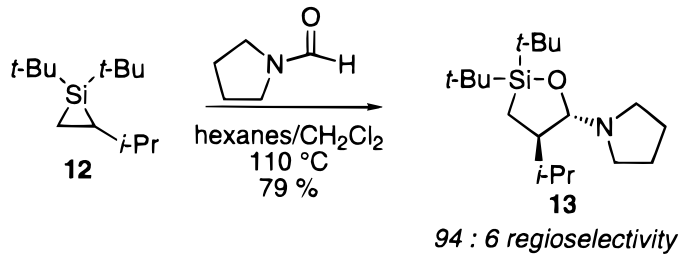

of $\mathbf{1 2}$ to give product $\mathbf{1 3}$ is also consistent with the intermediacy of a Lewis acid-base adduct such as $\mathbf{1 1}$. With silacyclopropane 12, two possible pentacoordinate siliconate intermediates, $\mathbf{1 4}$ and 15, must be considered. 


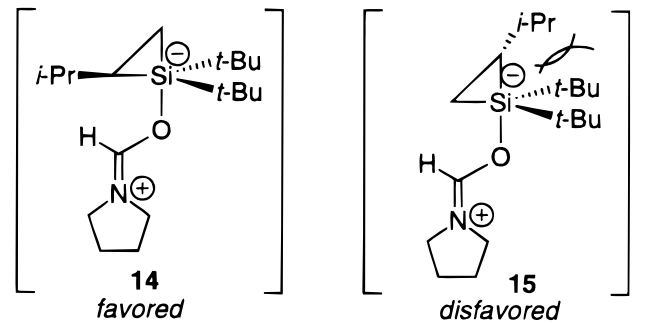

Whereas complex $\mathbf{1 5}$ suffers from steric repulsion between the tert-butyl groups on silicon and the axial isopropyl group, the alternate intermediate $\mathbf{1 4}$ does not. Reaction through siliconate $\mathbf{1 4}$ affords the observed product $\mathbf{1 3}$.

We envisioned that $\mathrm{N}, \mathrm{O}-$-acetals such as $\mathbf{1 0}$ and $\mathbf{1 3}$ would serve as precursors to oxocarbenium ions which could be transformed into more functionalized oxasilacyclopentanes, but the high acid sensitivity of these materials created some difficulties in their handling. Although these acetals could be handled under anhydrous and nonacidic conditions, exposure to even mildly acidic conditions (such as standing as solutions in $\mathrm{CDCl}_{3}$ ) led to extensive hydrolysis. We found it convenient to convert the formamide insertion products to more stable and synthetically useful acetates such as $\mathbf{1 6}$ (vide infra). For example, N,O-acetal $\mathbf{1 0}$ was hydrolyzed to a mixture of hemiacetals which was acetylated to obtain a single diastereomer of acetate $\mathbf{1 6}$ (eq 7). ${ }^{31,38}$ The stereochemistry

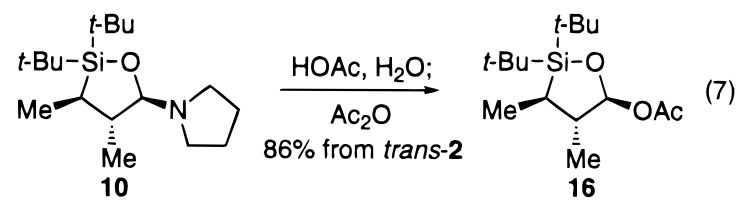

of $\mathbf{1 6}$, which has been proven by X-ray crystallography, ${ }^{39}$ is likely the thermodynamically favored diastereomer, since it is obtained from a mixture of hemiacetals. The route to acetate $\mathbf{1 6}$ could not be extended to the cisdimethyl analogue because the silacyclopropane cis-2 did not insert under the corresponding thermal conditions.

We developed an alternate route to the elusive cisdimethyl acetate $\mathbf{1 8}$ in the course of our studies of the ring-expansion of silacyclopropanes with isocyanides, a reaction first developed by Weidenbruch et al. ${ }^{40}$ The milder conditions of the isocyanide insertion allowed us to avoid the high-temperatures required for the formamide insertion. We demonstrated that this reaction proceeds with retention of silacyclopropane configuration (eqs 8 and 9). ${ }^{41}$ As with the reactions of formamides,
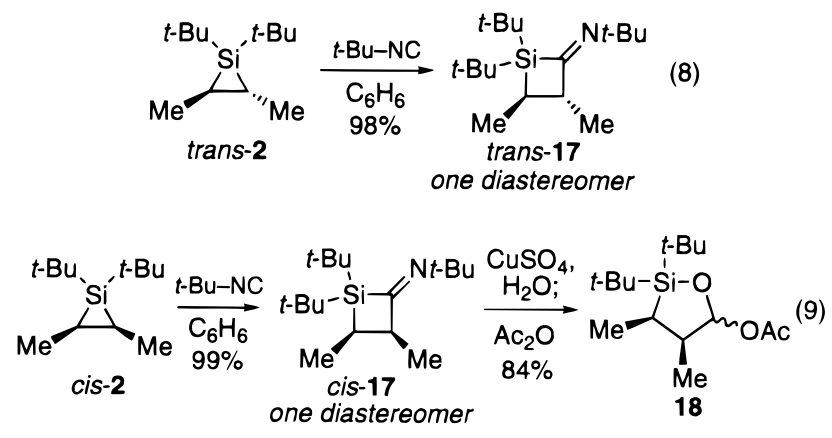

isocyanide insertions occur into the more substituted $\mathrm{C}-\mathrm{Si}$ bond of an unsymmetrical silacyclopropane. Treatment of the resulting iminosilacyclobutanes such as cis- $\mathbf{1 7}$ with mild acid led to hydrolysis of the $\mathrm{C}-\mathrm{Si}$ bond followed by imine hydrolysis. Acetylation of the resulting product afforded the previously inaccessible cis-dimethyl acetate 18 (eq 9). ${ }^{41}$

Concurrent with our research on the isocyanide insertion reaction (eqs 8 and 9), we were also searching for a way to catalyze the insertion of formamides into the thermally sensitive silacyclopropane cis-2. Acids and bases (both Brønsted and Lewis) were ineffective as catalysts for the amide insertion, primarily leading to decomposition or hydrolysis products. When we expanded our attempts to include metal salts, we observed that copper salts ( $10 \mathrm{~mol} \% \mathrm{Cul}, \mathrm{CuCN}$, or $\mathrm{CuBr}_{2}$ ) effectively catalyzed the amide insertion into cis-2, as well as silacyclopropanes trans-2 and $\mathbf{1 2}$, at or below room temperature. ${ }^{42}$ As with the thermal formamide insertions, stereospecific retention of configuration was observed (eqs 10 and 11). The copper-catalyzed insertion of a formamide into unsymmetrical silacyclopropane $\mathbf{1 2}$ occurred at the more substituted C-Si bond (eq 12), but with even higher regioselectivity (>99:1) than was observed previously.

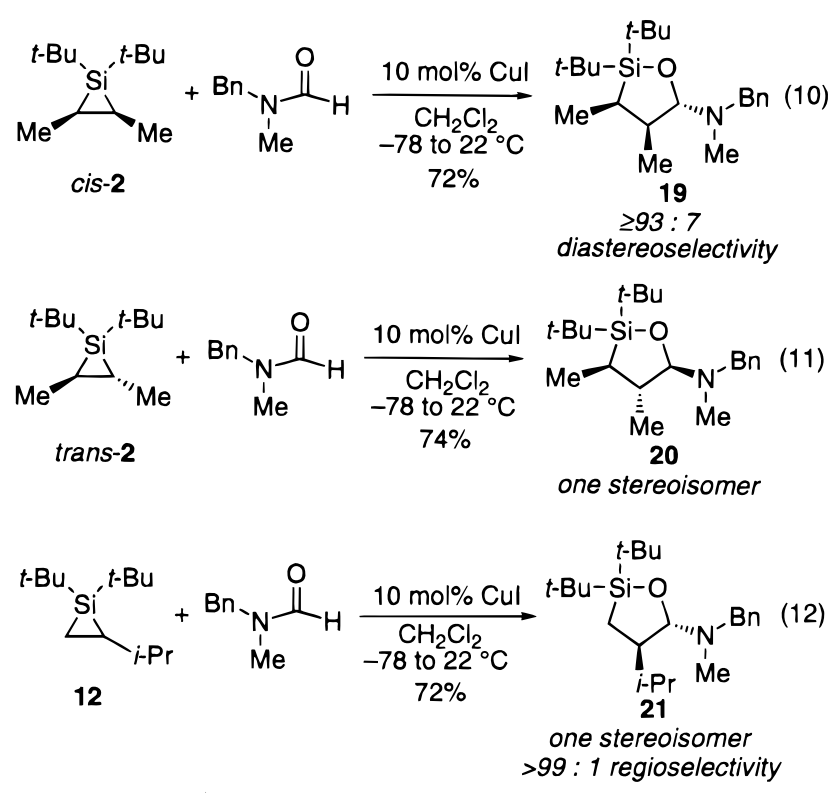

Based on a number of transformations designed to elucidate the mechanism, we believe that the coppercatalyzed insertion reaction proceeds by transmetalation of silicon to copper to form organocopper intermediate 22 (eq 13). ${ }^{42}$ The transmetalations of silanes to copper, ${ }^{43-46}$ as well as palladium, ${ }^{47}$ have been demonstrated previ-

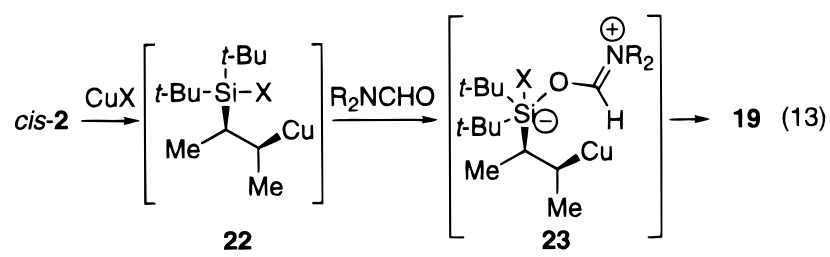

VOL. 33, N0. 11, 2000 / ACCOUNTS OF CHEMICAL RESEARCH 815 
ously. The activation of the amide toward nucleophilic attack likely occurs by silylation with the silyl halide ${ }^{48}$ generated in situ.

The discovery of the copper-catalyzed insertion not only provided milder conditions for amide insertion, but it also expanded the generality of the insertion reaction with respect to the carbonyl compound. For example, we had been unable to insert nonaromatic aldehydes or ketones under any conditions. Under the influence of copper catalysts, however, insertions of $\alpha, \beta$ unsaturated aldehydes and even esters (vide infra) were achieved with high diastereoselectivity and excellent regiocontrol (eq 14). Saturated aldehydes could not be coaxed into reaction, even at elevated temperatures (eq 15).

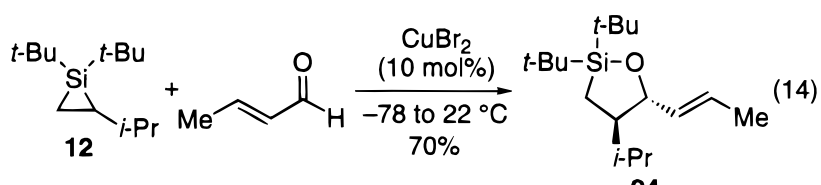

$$
\begin{aligned}
& 98: 2 \text { diastereoselectivity } \\
& >99: 1 \text { regioselectivity }
\end{aligned}
$$

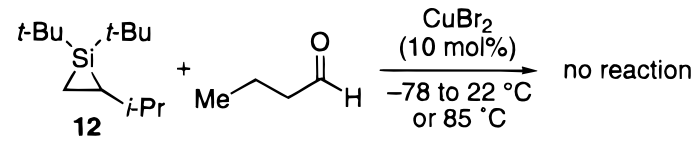

Our proposed transmetalation mechanism for the copper-catalyzed insertion reaction is consistent with the enhanced reactivity of $\alpha, \beta$-unsaturated aldehydes over their saturated analogues. The alkylcopper species formed upon transmetalation could undergo oxidative addition to form oxy- $\pi$-allyl intermediate 25 . Silylation of this species to form $\mathbf{2 6}$, followed by reductive elimination, would afford oxasilacyclopentane 24 (eq 16). This pathway would not be accessible to saturated aldehydes.

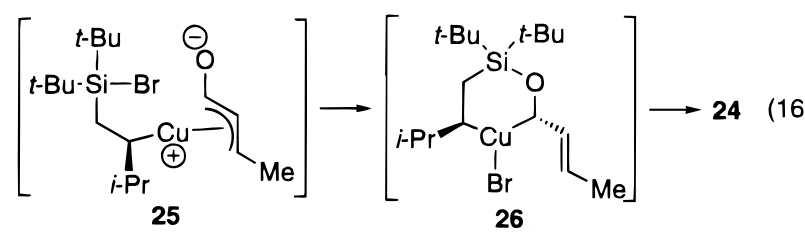

This mechanistic analysis led to the development of the insertion of saturated aldehydes into silacyclopropanes. We reasoned that the generation of organometallic intermediates from metal salts other than copper, including those incapable of oxidative addition processes, would allow a wider range of carbonyl compounds to insert. We tested this hypothesis experimentally and determined that zinc salts catalyze the insertions of aliphatic and aromatic aldehydes and ketones. To our surprise, the zinc-catalyzed insertions of substrates such as butyraldehyde occurred into the less substituted $\mathrm{C}-\mathrm{Si}$ bond with $>99: 1$ regioselectivity (eq 17). ${ }^{49}$ This experiment represents the first time that we had been able to functionalize the less substituted C-Si bond selectively.

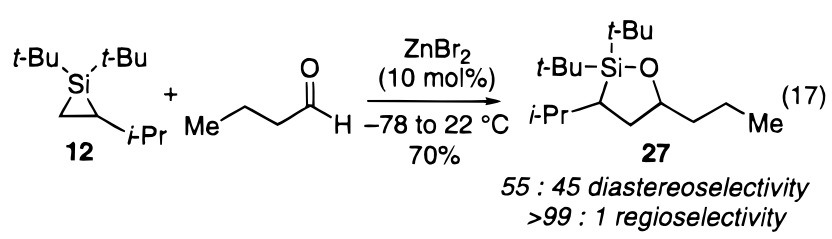

The complementary regioselectivity of insertion exhibited by different metal salt catalysts extends beyond saturated aldehydes to include the particularly powerful insertion of formate esters. By the appropriate choice of either zinc or copper salts, we can access either regioisomeric acetal $\mathbf{2 8}$ or $\mathbf{2 9}$ with >99:1 regioselectivity as mixtures of anomers (eqs 18 and 19). These acetals serve as precursors to oxocarbenium ions that have proven to be useful intermediates for the synthesis of polyoxygenated organic compounds (vide infra).

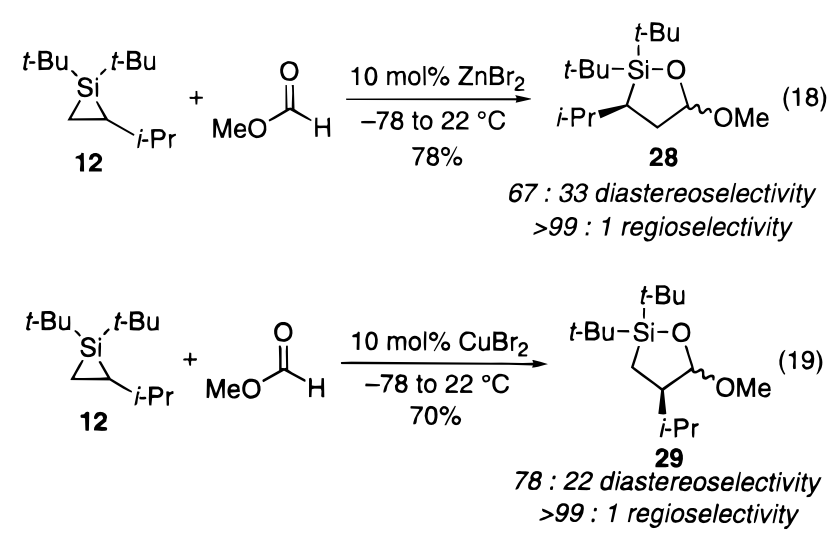

The differences in regioselectivity and reactivity observed for the zinc- and copper-catalyzed insertions (eqs 18 and 19) indicate that these reactions proceed by different pathways. In the case of the copper-catalyzed reaction, we have accumulated significant evidence that is consistent with a transmetalation mechanism. In contrast, $\mathrm{ZnBr}_{2}$ most likely activates the carbonyl compound, while the bromine atom may coordinate to the silicon atom of the silacyclopropane (as shown in transition structure 30) to enhance the nucleophilicity of the strained ring. This pathway is similar to the mechanisms proposed for the Lewis acid-catalyzed cyanosilation ${ }^{50}$ and hydrosilylation ${ }^{51}$ of aldehydes and ketones as well as the additions of other organometallic species to carbonyl compounds. ${ }^{52,53}$ Formation of the 1,3-regioisomer would occur to avoid unfavorable steric interactions between the substituent on the silacyclopropane and the carbonyl substrate as shown in 31.

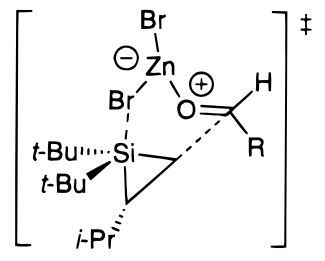

30

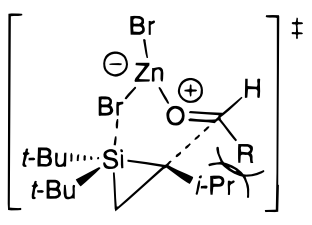

31

816 ACCOUNTS OF CHEM ICAL RESEARCH / VOL. 33, NO. 11, 2000 
In contrast to copper and zinc salts, palladium complexes catalyze different carbon-carbon bond-forming reactions of silacyclopropanes. The reactions of silacyclopropanes cis- and trans- $\mathbf{2}$ with alkynes in the presence of palladium catalysts allowed us to investigate the stereochemistry of both insertion and silylene-transfer processes. ${ }^{54,55}$ When cis- 2 was treated with phenylacetylene and a catalytic quantity $(0.2-3.0 \mathrm{~mol} \%)$ of $\mathrm{PdCl}_{2}\left(\mathrm{PPh}_{3}\right)_{2}$, two silicon-containing products were obtained (eq 20).

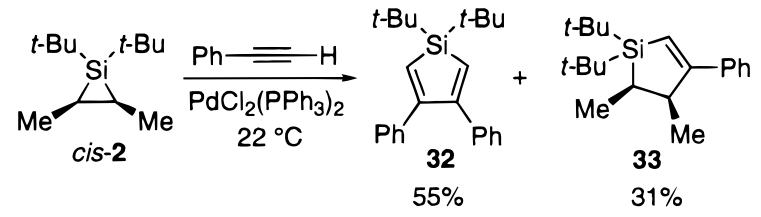

Silole 32, the product of reductive coupling of two alkynes by a silylene or silylenoid species, was accompanied by the production of cis-2-butene. ${ }^{56}$ In addition, insertion product $\mathbf{3 3}$ was formed with high diastereoselectivity as the cis stereoisomer. Silacyclopropane trans-2 also formed silole 32, accompanied by trans-2-butene, but only a trace amount of the insertion product (1\%) was observed. Investigations into the mechanism of these transformations suggested that they proceed by oxidative addition of in situ-generated $\mathrm{Pd}(0)$ complexes into the $\mathrm{C}-\mathrm{Si}$ bond of cis-2 to provide palladacyclobutane cis-34 (eq 21). ${ }^{56-58}$ Intermediate $\mathbf{3 4}$ can undergo stereospecific alkyne insertion or continue in the catalytic cycle to afford silole product 32.

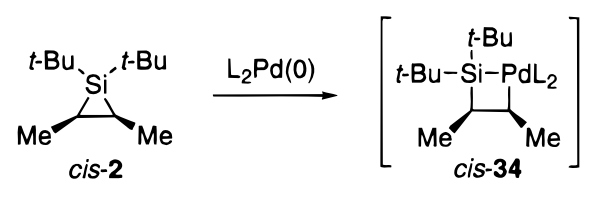

When internal alkynes were employed in reactions with palladium catalysts, silacyclopropenes such as 35 were obtained in high yield with no trace of silole products (eq 22). ${ }^{57} \mathrm{~A}$ control experiment verified that

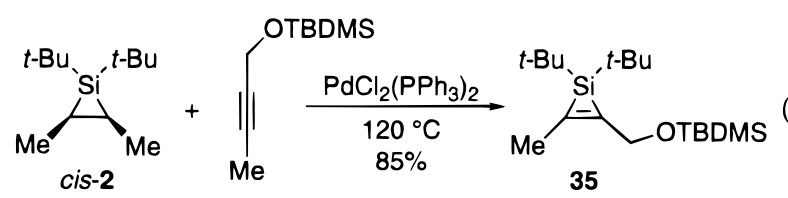

the palladium complex catalyzes silylene transfer. In the absence of a palladium catalyst, $<10 \%$ of silylene transfer is observed under conditions in which complete silyl transfer is observed with the catalyst. ${ }^{57} \mathrm{We}$ demonstrated that the palladium catalyst was still able to carry out oxidative addition on silane 35, but that this process must be reversible. The silacyclopropenation of alkynes shown in eq 22 represents a practical metal-catalyzed synthesis of these strained-ring silanes.

\section{Synthetic Applications of Silacyclopropane Reactions}

With the successful development of highly stereoselective carbon-carbon bond-forming reactions of silacyclopropanes, we explored the conversion of these insertion products into compounds that did not possess silicon atoms. The original plan, as outlined in eq 1 , led us to examine the oxidation of the $\mathrm{C}-\mathrm{Si}$ bonds in aldehyde insertion products such as 6 (eq 23). The $\mathrm{C}-\mathrm{Si}$ bond

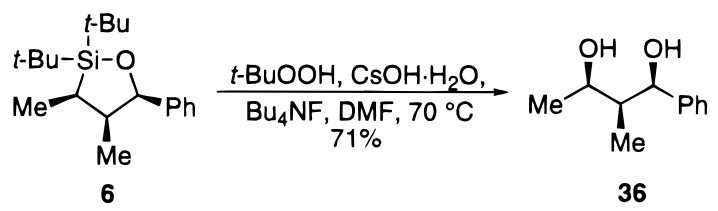

proved to be resistant to all modifications of the standard Tamao oxidation protocol because of the steric hindrance at the silicon atom. ${ }^{24-27}$ To circumvent this problem, we developed new conditions ${ }^{59}$ for the oxidation of silanes that employ a strong base, a fluoride source such as CsF or $\mathrm{Bu}_{4} \mathrm{NF}$, and $\mathrm{t}-\mathrm{BuOOH}$. Our basic conditions have proven to be useful for the oxidation of sterically hindered alkoxysilanes as well as phenylsilanes, particularly those acid-sensitive substrates that do not tolerate standard oxidation conditions. 60

Once we had demonstrated the ability to oxidize the $\mathrm{C}-\mathrm{Si}$ bonds of the insertion products, we wanted to use the oxasilacyclopentane acetates resembling $\mathbf{3 7}$ to access more highly functionalized compounds for synthetic applications (eq 24). In the presence of a Lewis acid, the

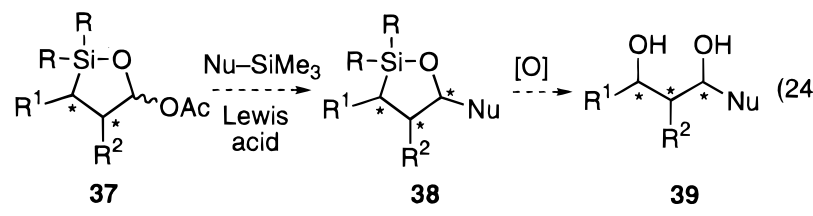

acetate moiety of $\mathbf{3 7}$ could act as a leaving group to generate an oxocarbenium ion which could then be attacked by nucleophiles (such as allylic silanes and silyl enol ethers) to afford substitution product 38. Oxidation of the product $\mathbf{3 8}$ to the resulting diol would provide a series of functionalized 1,3-diols 39 which were inaccessible using the aldehyde insertion reaction. To implement this plan, we set out to determine whether the nucleophilic substitution reactions would be stereoselective.

The reactions of oxasilacyclopentane acetals resembling 37 with nucleophiles in the presence of Lewis acids proceeded with high diastereoselectivity for a number of substrates. ${ }^{38,61,62}$ For example, the reaction of acetate $\mathbf{4 0}$ with allyltrimethylsilane afforded allylation product $\mathbf{4 1}$ with excellent diastereoselectivity (eq 25). The stereochemistry of this compound was determined by oxidation to the diol 42 (eq 26) and analysis of the derived acetonide. ${ }^{63}$ When a silyl enol ether such as $\mathbf{4 3}$ was used as a nucleophile, an additional stereocenter was also con- 
trolled to obtain product $\mathbf{4 4}$ with high diastereoselectivity (eq 27).
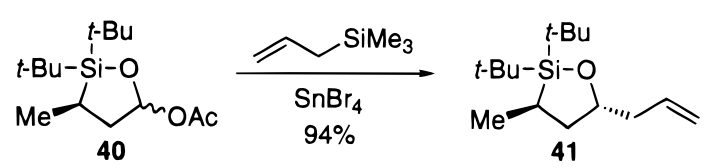

99 : 1 diastereoselectivity
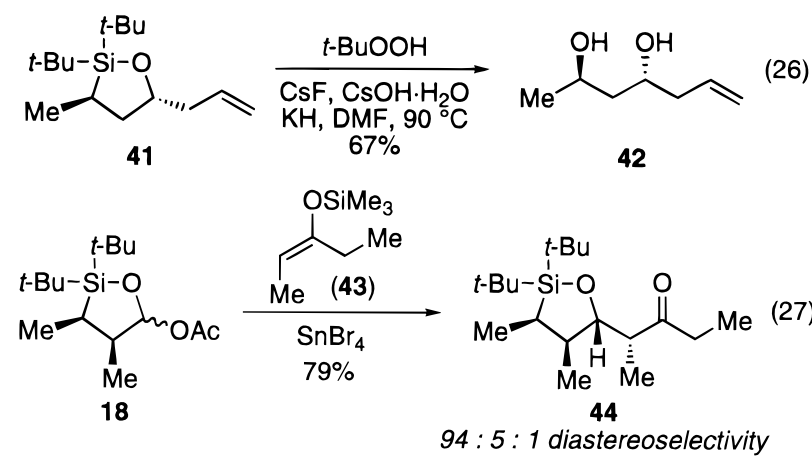

Predicting the sense of selectivity for the nucleophilic substitution reactions of oxasilacyclopentane acetals proved to be more difficult than initially expected. For example, we anticipated that the reaction of acetate $\mathbf{1 6}$ with allyltrimethylsilane would afford predominately the 1,2trans product. Instead, the 1,2-cis product was formed preferentially with excellent diastereoselectivity (Scheme 1). The stereochemistry of oxasilacyclopentane $\mathbf{4 6}$ was determined after oxidation and conversion to the acetonide 47. ${ }^{63,64}$ We observed similar contrasteric selectivities in the nucleophilic substitution reactions of sterically hindered tetrahydrofuran acetals. ${ }^{65}$ Our investigations of these unusual selectivities led us to pursue the factors that control the stereoselective reactions of five-membered ring oxocarbenium ions. This work has led to the development of a general stereoelectronic model for nucleophilic additions to five-membered oxocarbenium ions. ${ }^{66}$ Application of this model suggests that the 1,2-cis product $\mathbf{4 6}$ is the result of "inside attack" on oxocarbenium ion $\mathbf{4 5}$ from the bottom face (Scheme 1). ${ }^{62}$

\section{Scheme 1}

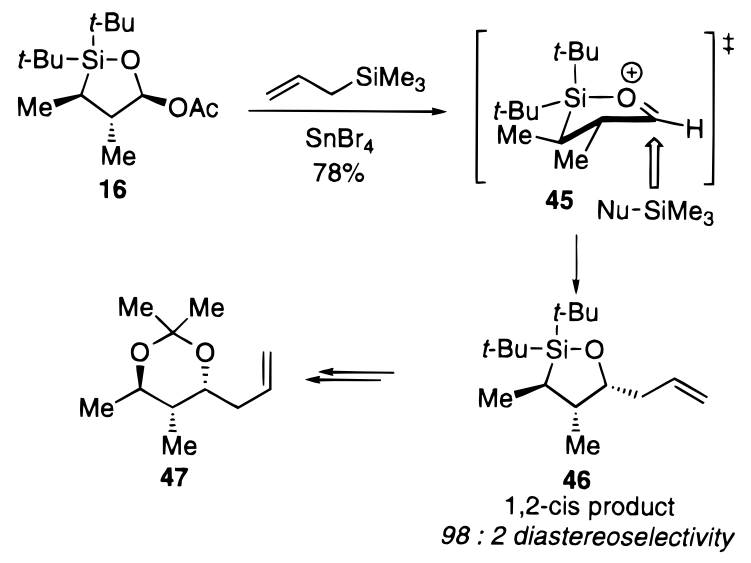

Recently, we have extended our studies of oxasilacyclopentane acetal chemistry by devising a two-step synthesis of oxasilacyclopentane acetals $\mathbf{4 8}$ from $\alpha, \beta$-unsat- urated esters (eq 28). ${ }^{67}$ Conjugate addition of a hydrosilyl<smiles>CC=CC(=O)OCC</smiles>

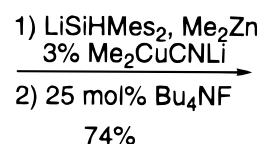<smiles>CCOC1O[Si](C)(C)C(C)C1[18O]</smiles>

anion to an enoate provided the $\beta$-hydrosilyl ester, which was capable of hydrosilylation in the presence of fluoride ion. Nucleophilic substitution on the resulting acetals $\mathbf{4 8}$ with allyltrimethylsilane proceeded with high diastereoselectivity (eq 29) to afford products 49 which are analogous to those obtained using silacyclopropane insertion methodology. We envisioned that this approach would be amenable to the preparation of enantiomerically pure oxasilacyclopentane acetals and allow us to access a more diverse array of products.

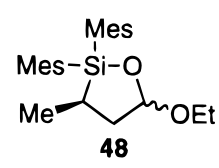

\section{New Directions}

Although our examples of stereoselective insertion and nucleophilic substitution reactions have proven the synthetic utility of strained-ring silicon compounds, we feel that there are still large advances to be made in this area. Our goal at the outset of this project was to expand the limited scope of carbon-carbon bond-forming reactions of silacyclopropanes to applications in stereoselective synthesis. Now, the limitations of this chemistry have shifted to the paucity of silacyclopropanes that are available. We plan to address this issue by developing the silacyclopropanation of functionalized chiral alkenes to obtain enantiomerically pure silacyclopropanes which can undergo further stereo- and regioselective insertion reactions. Ultimately, we envision employing a one-step protocol for the in situ silacyclopropanation and ringexpansion of an advanced synthetic intermediate to convert a chiral alkene to a stereodefined polyoxygenated moiety.

Our first advance in this direction is the diastereoselective silacyclopropanation of functionalized chiral alkenes. For example, silacyclopropanation of cyclohexene 50, which was prepared in two steps from 1,3-cyclohexadiene, ${ }^{68}$ afforded silane $\mathbf{5 1}$ as a single diastereomer (eq 30). Further transformations of this chiral silacyclopropane allowed us to construct highly substituted cyclohexanes such as $\mathbf{5 2}$ with high diastereoselectivity (eq 30).

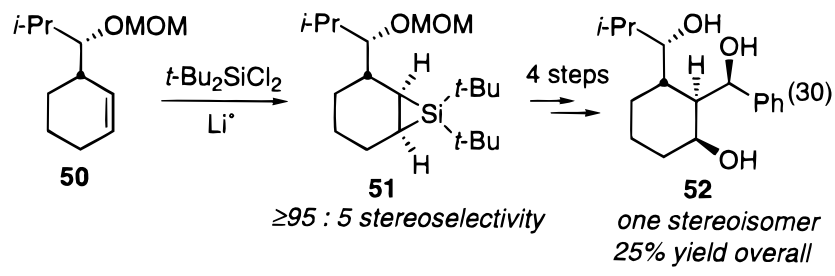

We are also exploring whether we can use the stereochemistry of oxasilacyclopentane products to influence the 
stereochemical outcomes of further transformations on these compounds. For example, the stereochemistry of silacyclopropane cis-2 was translated to the stereochemistry of the ethyl ketone $\mathbf{4 4}$ (eq 27), which might be used to control the stereochemistry of subsequent aldol reactions (eq 31). This sequence would allow access to highly oxygenated organic compounds rapidly and stereoselectively.
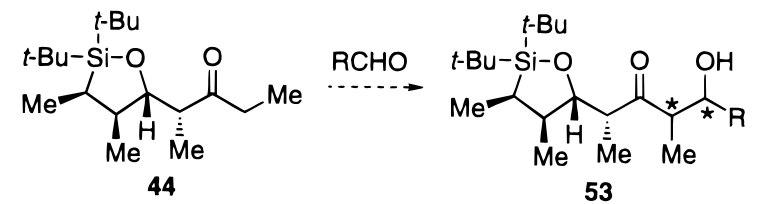

\section{Conclusion}

Although many challenges still lie ahead, we are closer to our goal of developing silacyclopropanes as intermediates for stereoselective organic synthesis. During our investigations, we have learned much about the reactivity of these strained-ring silanes and the stereochemistry of their ringopening reactions. We have shown that silacyclopropanes react with carbonyl compounds under mild conditions. These reactions are stereospecific, as well as highly stereo-, regio-, and chemoselective. By appropriate choice of catalyst, the regiochemistry of these reactions may be tuned to give the desired product. Stereoselective nucleophilic substitution reactions and stereospecific oxidation of the $\mathrm{C}-\mathrm{Si}$ bond to a carbon-oxygen bond allow silacyclopropanes to be converted to synthetically attractive 1,3diols for the synthesis of polyoxygenated organic molecules with several stereogenic centers.

We thank all of our co-workers who have made invaluable contributions to the development of this research; their names are included in the references list. This research was supported by the National Institutes of Health (General Medical Sciences) as well as the American Cancer Society, the Petrol eum Research Foundation, and the University of California Cancer Research Coordinating Committee. A.K.F. thanks Abbott Laboratories for a Graduate Research Fellowship. K.A.W. thanks AstraZeneca, the Camilleand Henry Dreyfus Foundation, Glaxo-Wellcome, Merck, the Research Corporation, and the Alfred P. Sloan Foundation for awards to support research.

\section{References}

(1) Sella, A.; Basch, H.; Hoz, S. Reactivity of Strained Compounds: Is Ground-State Destabilization the Major Cause for Rate Enhancement? J . Am. Chem. Soc. 1996, 118, 416-420.

(2) Sella, A.; Basch, H.; Hoz, S. Strain Release is not Enough. Tetrahedron Lett. 1996, 37, 5573-5576.

(3) Wong, H. N. C.; Hon, M.-Y.; Tse, C.-W.; Yip, Y.-C.; Tanko, J .; Hudlicky, T. Use of Cyclopropanes and Their Derivatives in Organic Synthesis. Chem. Rev. 1989, 89, 165-198.

(4) Doyle, M. P. Asymmetric Cyclopropanation. In Catalytic Asymmetric Synthesis; Ojima, I., Ed.; VCH: New York, 1993; pp 6399.

(5) Padwa, A.; Murphree, S. S. Three-Membered Ring Systems. In Progress in Heterocyclic Chemistry; Suschitzky, H., Scriven, E. F. V., Eds.; Pergamon: New York, 1994; Vol. 6, pp 56-73.

(6) Tanner, D. Chiral Aziridines-Their Synthesis and Use in Stereoselective Transformations. Angew. Chem., Int. Ed. Engl. 1994, 33, 599-619.

(7) Langkopf, E.; Schinzer, D. Uses of Silicon-Containing Compounds in the Synthesis of Natural Products. Chem. Rev. 1995, 95, 13751408.
(8) Fleming, I.; Barbero, A.; Walter, D. Stereochemical Control in Organic Synthesis using Silicon-Containing Compounds. Chem. Rev. 1997, 97, 2063-2192.

(9) Seyferth, D.; Annarelli, D. C. Hexamethylsilirane. A Simple, Isolable Silacyclopropane. J. Am. Chem. Soc. 1975, 97, 22732275.

(10) Seyferth, D.; Annarelli, D. C.; Vick, S. V.; Duncan, D. P. Hexamethylsilirane I. Preparation, Characterization, and Thermal Decomposition. J . Organomet. Chem. 1980, 201, 179-195.

(11) Seyferth, D.; Annarelli, D. C.; Shannon, M. L.; Escudie, J .; Duncan, D. P. Hexamethylsilirane II. Ring-Opening Reactions with Some Simple Reagents. J . Organomet. Chem. 1982, 225, 177-191.

(12) Seyferth, D.; Duncan, D. P.; Shannon, M. L.; Goldman, E. W. Hexamethylsilirane. 5. Conversion to Five-Membered Ring Silicon Compounds by "Two-Atom" Insertion Reactions of Aryl Olefins, 1,3-Dienes, and Conjugated Acetylenes. Organometallics 1984, 3, 574-578.

(13) Seyferth, D.; Duncan, D. P.; Shannon, M. L. Hexamethylsilirane. 6. Conversion to 1-Oxa-2-silacyclopentanes by "Two-Atom" Insertion Reactions of Aldehydes and Ketones. Organometallics 1984, 3, 579-583 and references therein.

(14) Saso, H.; Ando, W.; Ueno, K. Novel Si-C Bond Cleavages of Alkylidenesiliranes in the Reaction with Nucleophiles. Tetrahedron 1989, 45, 1929-1940.

(15) Boudjouk, P.; Black, E.; Kumarathasan, R.; Samaraweera, U.; Castellino, S.; Oliver, J. P.; Kampf, J . W. Synthesis, Structures, and Reactions of Sulfur and Selenium Insertion Products of 1,1Di-tert-butylsiliranes. Organometallics 1994, 13, 3715-3727.

(16) Pae, D. H.; Xiao, M.; Chiang, M. Y.; Gaspar, P. P. DiadamantylsiIylene and Its Stereochemistry of Addition. J. Am. Chem. Soc. 1991, 113, 1281-1288.

(17) Zhang, S.; Wagenseller, P. E.; Conlin, R. T. Stable 2-Vinylsiliranes. J. Am. Chem. Soc. 1991, 113, 4272-4278.

(18) Gordon, M. S.; Boatz, J. A.; Walsh, R. Heats of Formation of Alkylsilanes. J. Phys. Chem. 1989, 93, 1584-1585.

(19) Carbon-carbon bond formation using silacyclobutanes has been studied as well: Takeyama, Y.; Oshima, K.; Utimoto, K. Base Induced Reaction of Silacyclobutane with Aldehyde or Epoxide. Tetrahedron Lett. 1990, 31, 6059-6062.

(20) Bobbitt, K. L.; Gaspar, P. P. 1:2-Adducts from Silylene and 1,3Butadiene. J. Organomet. Chem. 1995, 499, 17-26.

(21) Tortorelli, V.J .; J ones, M., J r.; Wu, S.-h.; Li, Z.-h. Stereospecific Additions of Dimethylsilylene and Diphenylsilylene to Olefins. Organometallics 1983, 2, 759-764.

(22) Belzner, J .; Ihmels, H.; Kneisel, B. O.; Gould, R. O.; Herbst-Irmer, R. Reactions of a Cyclotrisilane with Olefins and Dienes: Evidence for an Equilibrium Between Silylenes and a Cyclotrisilane. Organometallics 1995, 14, 305-311.

(23) Boudjouk, P.; Samaraweera, U.; Sooriyakumaran, R.; Chrusciel, J .; Anderson, K. R. Convenient Routes to Di-tert-butylsilanediyl: Chemical, Thermal and Photochemical Generation. Angew. Chem., Int. Ed. Engl. 1988, 27, 1355-1356.

(24) Tamao, K.; Ishida, N.; Tanaka, T.; Kumada, M. Hydrogen Peroxide Oxidation of the Silicon-Carbon Bond in Organoalkoxysilanes. Organometallics 1983, 2, 1694-1696.

(25) Tamao, K. Oxidative Cleavage of the Silicon-Carbon Bond; Development, Mechanism, Scope, and Limitations. In Advances in Silicon Chemistry; Larson, G. L., Ed.; J Al: Greenwich, CT, 1996; Vol. 3, pp 1-62.

(26) Fleming, I. Silyl-to-Hydroxy Conversion in Organic Synthesis. Chemtracts-Org. Chem. 1996, 9, 1-64.

(27) J ones, G. R.; Landais, Y. The Oxidation of the Carbon-Silicon Bond. Tetrahedron 1996, 52, 7599-7662.

(28) Bodnar, P. M.; Palmer, W. S.; Shaw, J. T.; Smitrovich, J. H.; Sonnenberg, J. D.; Presley, A. L.; Woerpel, K. A. Stereo- and Regiochemistry of Aldehyde Insertions into the $\mathrm{C}-\mathrm{Si}$ Bonds of Siliranes. J . Am. Chem. Soc. 1995, 117, 10575-10576.

(29) Bodnar, P. M.; Palmer, W. S.; Ridgway, B. H.; Shaw, J. T.; Smitrovich, J. H.; Woerpel, K. A. Stereo- and Regioselectivity of Reactions of Siliranes with Aldehydes and Related Substrates. J . Org. Chem. 1997, 62, 4737-4745.

(30) Chuit, C.; Corriu, R. J . P.; Reye, C.; Young, J . C. Reactivity of Pentaand Hexacoordinate Silicon Compounds and Their Role as Reaction Intermediates. Chem. Rev. 1993, 93, 1371-1448.

(31) Shaw, J. T.; Woerpel, K. A. Stereoselective Insertion of Formamides into the C-Si Bond of Siliranes. J. Org. Chem. 1997, 62, $442-443$.

(32) Kahne, D.; Still, W. C. Hydrolysis of a Peptide Bond in Neutral Water. J. Am. Chem. Soc. 1988, 110, 7529-7534.

(33) Sullivan, S. A.; DePuy, C. H.; Damrauer, R. Gas-Phase Reactions of Cyclic Silanes. J. Am. Chem. Soc. 1981, 103, 480-481. 
(34) Myers, A. G.; Kephart, S. E.; Chen, H. Silicon-Directed Aldol Reactions- Rate Acceleration by Small Rings. J . Am. Chem. Soc. 1992, 114, 7922-7923.

(35) Denmark, S. E.; Griedel, B. D.; Coe, D. M.; Schnute, M. E. Chemistry of Enoxysilacyclobutanes: Highly Selective Uncatalyzed Aldol Additions. J. Am. Chem. Soc. 1994, 116, 7026-7043.

(36) Chaplinski, V.; de Meijere, A. A Versatile New Preparation of Cyclopropylamines from Acid Dialkylamides. Angew. Chem., Int. Ed. Engl. 1996, 35, 413-414.

(37) Kobayashi, S.; Nishio, K. Facile and Highly Stereoselective Synthesis of Homoallylic Alcohols Using Organosilicon Intermediates. J. Org. Chem. 1994, 59, 6620-6628.

(38) Shaw, J. T.; Woerpel, K. A. Preparation and Synthetic Utility of Oxasilacyclopentane Acetals Derived from Siliranes. Tetrahedron 1997, 53, 16597-16606.

(39) Bear, T. J .; Woerpel, K. A.; Ziller, J . University of California, Irvine, unpublished results.

(40) Kroke, E.; Willms, S.; Weidenbruch, M.: Saak, W.; Pohl, S. Marsmann, H. Siliranes: Formation, Isonitrile Insertion, and Thermal Rearrangements. Tetrahedron Lett. 1996, 37, 3675-3678.

(41) Nguyen, P. T.; Palmer, W. S.; Woerpel, K. A. Stereospecific and Regioselective Isocyanide Insertions into Silacyclopropanes to Form Iminosilacyclobutanes and Subsequent Ring-Expansion Reactions. J. Org. Chem. 1999, 64, 1843-1848.

(42) Franz, A. K.; Woerpel, K. A. Stereospecific and Regioselective Reactions of Silacyclopropanes with Carbonyl Compounds Catalyzed by Copper Salts: Evidence for a Transmetalation Mechanism. J. Am. Chem. Soc. 1999, 121, 949-957.

(43) Ikegashira, K.; Nishihara, Y.; Hirabayashi, K.; Mori, A.; Hiyama, T. Copper(I) Salt Promoted Homo-coupling Reaction of Organosilanes. Chem. Commun. 1997, 1039-1040.

(44) Ito, H.; Sensui, H.; Miura, K.; Hosomi, A. New Access to CrossCoupling Reaction between Arylsilanes or Heteroarylsilanes and Aryl Halides Mediated by a Copper(I) Salt. Chem. Lett. 1997, 639640.

(45) Ito, H.; Arimoto, K.; Sensui, H.; Hosomi, A. Direct Alkynyl Group Transfer from Silicon to Copper: New Preparation Method of Alkynylcopper (I) Reagents. Tetrahedron Lett. 1997, 38, 39773980.

(46) Kang, S.-K.; Kim, T.-H.; Pyun, S.-J . Copper(I)-catalysed Homocoupling of Organosilicon Compounds: Synthesis of Biaryls, Dienes and Diynes. J. Chem. Soc., Perkin Trans. 1 1997, 797798.

(47) Hatanaka, Y.; Hiyama, T. Stereochemistry of the Cross-coupling Reaction of Chiral Alkylsilanes with Aryl Triflates: A Novel Approach to Optically Active Compounds. J. Am. Chem. Soc. 1990, 112, 7793-7794.

(48) Lang, R. W. Fluorine-Containing Organozinc Reagents, Part III: A New Formylation Reaction of Fluoroalkylzinc Halides. Helv. Chim. Acta 1988, 71, 369-373.

(49) Franz, A. K.; Woerpel, K. A. University of California, Irvine, unpublished results.

(50) Evans, D. A.; Carroll, G. L.; Truesdale, L. K. Synthetic Applications of Trimethylsilyl Cyanide. An Efficient Synthesis of $\beta$-Aminomethyl Alcohols. J. Org. Chem. 1974, 39, 914-917.

(51) Kunz, H.; Sager, W.; Pfrengle, W.; Schanzenbach, D. Reversal of Asymmetric Induction in Stereoselective Strecker Synthesis on Galactosyl Amine as the Chiral Matrix. Tetrahedron Lett. 1988 29, 4397-4400.
(52) For a review describing the mechanism of nucleophilic additions of organozinc compounds to carbonyl compounds, see: Noyori, R.; Kitamura, M. Enantioselective Addition of Organometallic Reagents to Carbonyl Compounds: Chirality Transfer, Multiplication, and Amplification. Angew. Chem., Int. Ed. Engl. 1991, 30, 46-69.

(53) For a discussion of the addition of alkylaluminum compounds to carbonyl compounds, see: Ashby, E. C.; Smith, R. S. Organometallic Reaction Mechanisms XVIII. Concerning the Nature of the Transition State in the Reaction of Trialkylaluminum Compunds with Ketones. J. Organomet. Chem. 1982, 225, 71-85.

(54) Seyferth, D.; Shannon, M. L.; Vick, S. C.; Lim, T. F. O. Silacyclopropenes. 3. Palladium-Catalyzed Insertion Reactions. Organometallics 1985, 4, 57-62.

(55) Ishikawa, M.; Ohshita, J.; Ito, Y.; lyoda, J. Silicon-Carbon Unsaturated Compounds. 22. The Formation and Reactions of a Nickelasilacyclobutene. J. Am. Chem. Soc. 1986, 108, 7417-7419 and references therein.

(56) Palmer, W. S.; Woerpel, K. A. Stereospecific Palladium-Catalyzed Reactions of Siliranes with Acetylenes. Organometallics 1997, 16, 1097-1099.

(57) Palmer, W. S.; Woerpel, K. A. Synthesis of Silirenes by PalladiumCatalyzed Transfer of Silylene from Siliranes to Alkynes. Organometallics 1997, 16, 4824-4827.

(58) Palmer, W. S.; Woerpel, K. A. University of California, Irvine, unpublished results.

(59) Smitrovich, J . H.; Woerpel, K. A. Oxidation of Sterically Hindered Alkoxysilanes and Phenylsilanes Under Basic Conditions. J . Org. Chem. 1996, 61, 6044-6046.

(60) Molander, G. A.; Nichols, P. J . Total Synthesis of ( \pm )-Epilupinine via an Organoyttrium-Catalyzed Sequential Cyclization/Silylation Reaction. J. Org. Chem. 1996, 61, 6040-6043.

(61) Shaw, J. T.; Woerpel, K. A. Divergent Diastereoselectivity in the Addition of Nucleophiles to Five-membered Ring Oxonium lons. J. Org. Chem. 1997, 62, 6706-6707.

(62) Bear, T. J .; Shaw, J . T.; Woerpel, K. A. University of California, Irvine, unpublished results.

(63) Rychnovsky, S. D.; Rogers, B. N.; Richardson, T. I. Configuration Assignment of Polyene Macrolide Antibiotics Using the $\left.{ }^{13} \mathrm{C}\right]$ Acetonide Method. Acc. Chem. Res. 1998, 31, 9-17.

(64) Evans, D. A.; Rieger, D. L.; Gage, J . R. ${ }^{13}$ C NMR Chemical Shift Correlations in 1,3-Diol Acetonides. Implications for the Stereochemical Assignment of Propionate-Derived 1,3-Polyols. Tetrahedron Lett. 1990, 31, 7099-7100.

(65) Shaw, J . T.; Woerpel, K. A. Divergent Diastereoselectivity in the Addition of Nucleophiles to Furan-Derived Oxonium Ions. Tetrahedron 1999, 55, 8747-8756.

(66) Larsen, C. H.; Ridgway, B. H.; Shaw, J. T.; Woerpel, K. A. A Stereoelectronic Model to Explain the Highly Stereoselective Reactions of Nucleophiles with Five-membered-Ring Oxocarbenium lons. J. Am. Chem. Soc. 1999, 121, 12208-12209.

(67) Blair, S. A.; Tenenbaum, J. M.; Woerpel, K. A. University of California, Irvine, unpublished results.

(68) Brown, H. C.; Bhat, K. S. Hydroboration. 76. Hydroboration of Cyclic Dienes with Representative Hydroborating Agents. J . Org. Chem. 1986, 51, 445-449.

\section{AR9900562}

